\title{
Metodologias participativas e projeto UCA: a busca pela tecnologia como cultura
}

\author{
Magda Pischetola* \\ Lyana Thediga Miranda**
}

\section{Resumo}

No contexto complexo e mutável da cultura digital, as mídias se constituem em um importante espaço para a formação, tendo o importante papel de articular novas lógicas culturais que acarretam em rupturas para o âmbito escolar. Para compreender essa mudança, criam-se novos métodos de análise e investigação - as Metodologias Participativas -, estratégias de pesquisa-ação cujo objetivo é intervir em uma dada situação social. No foco da análise aqui proposta, tais metodologias ajudam a confrontar o desafio de envolver as tecnologias digitais na cultura da escola, por meio da participação dos diferentes sujeitos envolvidos. Dois estudos de caso qualitativos sobre o projeto Um Computador por Aluno, realizados em 2012 nas escolas de Santa Catarina e Bahia, constituem a primeira etapa da pesquisa apresentada. Os resultados dizem respeito a uma inserção da tecnologia de forma "verticalizada" e a um processo desmotivador que atravessa diversas instâncias das escolas, desde o planejamento até as relaçôes em sala de aula. A partir dessas consideraçóes, a segunda etapa de pesquisa propóe uma intervenção didático-pedagógica em uma das quatro escolas investigadas. As metodologias de vídeo e fotografia participativas sáo escolhidas como possibilidades de ação-reflexão-ação que tematizam a própria realidade sociocultural, agregando o potencial de compartilhamento das experiências. Os resultados apontam para a importância da realização de atividades criativas, adequadas a uma concepçáo social de aprendizagem, para a centralidade da agência de crianças e jovens, junto à necessidade de redefinir as relaçôes entre professor e aluno, em uma perspectiva mais "horizontal" do processo de ensino-aprendizagem.

Palavras-chave: Projeto UCA. Metodologia da Pesquisa. Educação para a Participação.

* Doutora em Educaçáo pela Università Cattolica del Sacro Cuore di Milano, Itália. Professora do Departamento de Educaçáo da Pontifícia Universidade Católica do Rio de Janeiro.

** Mestre e Doutoranda em Educação pela Universidade Federal de Santa Catarina (UFSC). 


\section{Mídias como espaço de formação: a perspectiva das Metodologias Participativas}

Na perspectiva de convergência apontada por Jenkins (2011), as mídias e tecnologias digitais se caracterizam como objetos sociais que se constituem em um importante espaço para as relaçóes e, também, para a formação. Longe de ser um lugar apaziguador, esse é um cenário que acarreta deslocamentos dos temas constantes da escola tais como: a centralidade - da própria instituição como "o" lugar do conhecimento, e do professor como o guardião desse saber; sua constituição cultural e, como consequência, seu valor como instituidora de um modelo de letramento e postura crítica frente à realidade.

Nesse contexto de mudanças, as mídias e tecnologias digitais têm o importante papel de articular (e não instituir) novas lógicas culturais que acarretam em rupturas para o âmbito escolar. A esse respeito, dentre as necessidades apontadas por Rivoltella (2012), enfatizamos a urgência em ponderarmos outros espaços-tempos formativos, ampliando-os para além da escola e estendendo-os para todas as idades e períodos da vida - familiar, social, cultural, entre outros. Para compreender essa mudança, é imperativo que se criem novos métodos de análise e investigação.

Com essa demanda, apontamos a importância das Metodologias Participativas, uma vez que possuem como característica principal a flexibilidade, predicado de um contexto complexo e mutável como o da cultura digital. Ou seja, são técnicas que se adequam aos contextos investigados de forma a propiciar a atuação dos diferentes atores na construção coletiva de atividades, intervençôes ou demandas voltadas à resolução de problemas - sejam eles socioculturais, socioambientais ou, ainda, educativos.

\section{Metodologias Participativas: definiçáo, desafios e possibilidades}

Constituídas como abordagens de comunicação participativas (WHITE; NAIR, 1994), as Metodologias Participativas são estratégias de promoção e participação com o objetivo de intervir e mudar uma dada situação social, chamando atenção para ela e instituindo, dessa forma, um debate público sobre determinado tema. Com um enfoque participativo, permite a açáo efetiva dos sujeitos envolvidos, não apenas considerando e valorizando seus conhecimentos, experiências e desejos, mas envolvendo-os na discussão, de forma a explorar soluçôes colaborativas para problemas que emergem do seu cotidiano. Nessa busca, o sentido de empoderamento está sempre presente. São metodologias que aspiram por uma apropriação e uma produção crítica, criativa e cidadá, como possibilidade de reflexão e de participação na cultura digital temas caros também a Mídia-educação (BELLONI, 2012; BUJOKAS; ROTHBERG, 
2014; FANTIN, 2006; FANTIN; RIVOLTELLA, 2012; GIRARDELLO; OROFINO, 2012).

Assim, o viés pautado na transformação social e na prática cidadá, que implica uma coparticipação dos diferentes atores, torna-se prática constante em investigaçóes sobre os movimentos sociais e socioambientais, além da participação social em gestão de políticas públicas (BANDEIRA, 1999; BROSE, 2001; SANTOS, 2005; WHITE; NAIR, 1994). Dentre os diversos instrumentos que utilizam, como base, à atuação dos sujeitos como observadores atentos do seu cotidiano e de suas práticas, ressaltamos a Pesquisa Participante (BRANDÁO, 1999) e a Pesquisa-ação (THIOLLENT, 2000; TRIPP, 2012).

No foco da análise aqui proposta, tais metodologias nos ajudam a confrontar, na prática cotidiana da escola, o desafio de envolver as tecnologias digitais no contexto da cultura, por meio de processos que abarcam a participaçáo dos diferentes sujeitos envolvidos - professores, alunos e gestores - na busca por tomadas de decisão coletivas.

Com a perspectiva participativa na escola, estamos falando de algo que, longe de ser uma novidade, já foi realizado nas pedagogias fundadas por Freinet e Freire. Trata-se de tornar a aprendizagem um processo participativo e colaborativo, para que os alunos de todas as idades sejam tomados como sujeitos ativos, críticos e pensantes. Assim, nos voltamos a Freire (2011), quando este aponta que a Educação também se dá nessa relação dialógica entre cultura e ambiente, que recusa os olhares uniformizados ao mesmo tempo em que admite as diversas comunicaçóes nesse processo. Retornamos, ainda, Freinet (1974), para quem a participação ativa de crianças e jovens em toda a ação educativa - deslocando o professor do centro do saber para localizá-lo ao lado, como mediador em um processo de ensino-aprendizagem - parte da realidade que os circunda.

Assim, a intenção do texto é qualificar a relação entre educação e tecnologia, buscando superar a visão determinista da tecnologia de forma a observá-la para além do acesso à máquina e à infraestrutura, no sentido de uma inclusão cidadã na cultura digital. Para tanto, acreditamos que a inclusão digital pressupóe uma mudança paradigmática das práticas de ensino-aprendizagem, ultrapassando a perspectiva utilitarista sobre as novas tecnologias e em prol da valorização do sujeito que aprende.

Um aluno que não só desenvolve habilidades técnicas de uso da tecnologia digital, mas que tem práticas sociais, relaçôes com seu contexto sociocultural, formas de pensamento críticas e pessoais. Isso representa um desafio à ideia de que a inclusão digital seja apenas um problema econômico ou infraestrutural e tenta considerá-la de um ponto de vista mais amplo, como problema cultural (FANTIN, 2006; LEMOS, 2007; PISCHETOLA, 2011; RIVOLTELLA, 2012). 


\section{Uma intervençáo no contexto do projeto UCA}

A investigação aqui apresentada tem por enfoque o projeto Um Computadorpor Aluno (UCA), iniciativa da Presidência da República desenvolvida em conjunto com o Ministério da Educação (MEC). $\mathrm{O}$ projeto vincula-se às açôes do Plano de Desenvolvimento da Educação (PDE), do Programa Nacional de Tecnologia Educacional (ProInfo) ${ }^{1}$. Sua finalidade é a de promover a inclusão digital mediante a aquisição e a distribuição de laptops em escolas públicas espalhadas nos diferentes estados do Brasil.

Perseguindo a compreensão de um paradigma que parece responder às necessidades sentidas em contexto educativo, procuramos pesquisar três aspectos principais da introdução da tecnologia em sala de aula: o desenvolvimento de habilidades dos alunos, a motivaçáo de aprender gerada pelo uso de tecnologia em sala de aula, a adaptaçáo dos professores ao novo contexto de trabalho focado na centralidade do aluno. A partir do entendimento da tecnologia como cultura, três hipóteses guiam a pesquisa.

A primeira hipótese é a que embasa a missão do projeto UCA, ou seja, que o uso da tecnologia móvel em sala de aula gera uma mudança na aquisição de habilidades e, especificamente: a autonomia na resolução de problemas; as práticas de colaboração e compartilhamento dos conhecimentos; a ocorrência do letramento digital nas realidades pesquisadas, entendido como condiçáo que o sujeito adquire uma vez que incorpora a leitura e a escrita em seu viver.

A segunda hipótese é que a motivação influencia de maneira substancial o desenvolvimento de novas habilidades. Embora saibamos que é difícil extrapolar os fatores de motivaçáo no processo de aprendizagem, pesquisas revelam que eles se relacionam com o gozo pessoal, o interesse, o prazer de se envolver em uma atividade (BOEKAERTS, 2002; BORUCHOVITCH; BZUNECK, 2009).

A terceira hipótese do trabalho aborda a importância da reação do professor à nova tecnologia. Segundo a abordagem construtivista que guia o projeto UCA, em consequência da nova organização da sala de aula com a tecnologia móvel, o professor atua com um papel de "mediador", levando o aluno a perseguir objetivos de aprendizagem através de resoluçáo independente de problemas. Dessa forma, a pesquisa tem por objetivo entender quais são as metodologias didáticas de mais sucesso neste sentido. Essa terceira hipótese é a mais importante, pois tem uma influência também nas primeiras duas. 


\section{Projeto UCA em Santa Catarina e Bahia: dois estudos de caso}

O trabalho de campo foi realizado ao longo do ano letivo de 2012 nos estados de Santa Catarina e da Bahia e envolveu quatro escolas públicas de ensino básico: duas situadas em cidades capitais - Florianópolis (SC) e Salvador (BA) - e duas no interior dos dois estados - Jaraguá do Sul (SC) e Feira de Santana (BA).

A investigação orientou-se na direção da abordagem qualitativa da pesquisaação (THIOLLENT, 2000; TRIPP, 2012), sendo prevista sua realização em duas etapas. A primeira etapa consistiu na análise das necessidades de cada contexto, enquanto a segunda teve por objetivo uma intervenção didático-pedagógica em uma das escolas pesquisadas, pautada nas necessidades reveladas na primeira fase da investigação. Para tanto, utilizamos a perspectiva das Metodologias Participativas no intuito de abarcar o uso das tecnologias digitais móveis para além do viés instrumental e de forma a aproximar tais atividades ao contexto da cultura digital.

A metodologia elaborada para o primeiro momento de investigação utilizou-se dos seguintes instrumentos de pesquisa:

- observação participante das atividades de ensino-aprendizagem com o UCA em 10 turmas;

- entrevistas semiestruturadas com 25 professores, diretores e coordenadores do projeto;

- grupos focais com 6-8 alunos, por um total de 10 grupos focais (um por cada turma).

A metodologia de intervenção didático-pedagógica elaborada para o segundo momento da pesquisa aproximou-se das metodologias do Vídeo Participativo (WHITE, 2003; ZANOTTI, 2013) e da Fotografia Participativa (MEIRINHO, 2014), como possibilidades de ação-reflexão-ação que tematizam a própria realidade sociocultural, agregando o potencial de compartilhamento de suas experiências.

\section{Resultados da primeira etapa: a importância de motivaçáo e regulaçáo}

O referencial teórico que fundamenta a análise de dados orienta-se a partir da abordagem metodológica da Grounded Theory (GLASER; STRAUSS, 1967), baseada na interpretação de categorias gerais, a partir de uma leitura indutiva das transcriçóes de entrevistas e grupos focais e das situaçôes observadas nos diferentes contextos escolares. Os resultados permitem responder, ao menos parcialmente, às três hipóteses formuladas. 


\section{- Aquisiçáo de habilidades: aprendizagem online?}

A maioria dos professores afirma ter detectado um alto nível de engajamento dos alunos com o laptop, especialmente do ponto de vista da troca de informação, da interação nas atividades lúdicas e da comunicação social. Jogos online e bate-papo nas redes sociais - Orkut, Facebook, Twitter, Msn, Youtube, Tumblr, MySpace - estão entre as atividades que os alunos dizem preferir (PISCHETOLA, 2014). Ou seja, a possibilidade mais interessante do laptop é sem dúvida sua conectividade. Curiosamente, esse dado apareceu também nas escolas da Bahia, onde a conexáo a Internet ainda é muito precária, quando não inexistente:

Menina: Felicidade, eu botei, que ajuda a pessoa a ser alegre, quando você tá triste é só ir no Youtube ver um vídeo engraçado e com isso você fica alegre. O futuro, eu botei, que ajuda a escolher um futuro melhor, porque tem coisas que a gente não sabe a gente pode pesquisar na internet a gente vai até conseguir, dai agente vai procurando, procurando até conseguir e ajuda no futuro e na carreira. (Grupo focal $5^{\circ}$ ano).

\section{Menina: Eu botei um monte de pessoa no carnaval.}

Pesquisadora: Por quê?? Por que você botou essa imagem?

Menina: Porque traz conhecimento.

Pesquisadora: Por que você acha que o laptop traz conhecimento? Menina: Porque a gente pesquisa coisas na Internet. (Grupo focal $6^{\circ}$ ano).

Ao mesmo tempo, o desempenho dos alunos não melhorou significativamente em termos de utilização estratégica do laptop. Muitos dos professores entrevistados destacaram que a nova tecnologia trouxe falta de atenção e distração em sala de aula ${ }^{2}$, e que a aprendizagem mais evidente de seus alunos foi principalmente relacionada com o desenvolvimento de habilidades técnicas (36\% dos entrevistados) e com a autonomia de pesquisa (26\%). A colaboração foi mencionada por um quarto dos entrevistados e, quase sempre, como sinônimo de ajuda mútua e/ou interação social.

Um dado muito interessante é também a presença nos depoimentos das crianças de muitos aspectos negativos relacionados com as atividades na Internet. No caso de alunos mais velhos e com disponibilidade de conexão a Internet, o aspecto negativo mencionado tem a ver com a dispersão e distraçáo causada pelo laptop. Por outro lado, no caso em que as crianças não apresentavam muitas experiências de navegação na Internet - por serem mais novas e/ou de origem mais humilde -, as práticas de comunicação e jogo online são vistas com medo, talvez refletindo outras preocupaçóes 
que a criança vive em seu contexto social. Procurando uma resposta à nossa primeira hipótese, notamos que, em ambos os casos, as práticas de comunicação atuadas pelas crianças levam a uma autorreflexão interessante.

Menino: Eu botei um bagulhete de mensagens significa comunidade, porque essa coisa esta estragando os estudos, muita gente não presta atenção nas aulas, um bando de viciados no Tumblr, as pessoas aqui que estäo presentes.

Pesquisadora: Evocê não usa as redes sociais?

Menino: Eu não, eu deixo em casa, o computador da escola eu deixo em casa, só pra fazer trabalho.

Pesquisadora: Você já usou pra rede social?

Menino: Já, ano passado eu era o maior viciado, ai por isso que eu rodei, sabe. Na oitava serie estou a segunda vez, tenho duas camisas deformados.

Pesquisadora: Você já reprovou, entáo você náo usa mais as redes sociais, éisso?

Menino: Não uso mais porque me prejudicou. (Grupo focal $8^{\mathrm{a}}$ série).

Menina: Tem coisas que criança näo pode ver. [...] Eles vêm o que a gente fica vendo, o que a gente tá fazendo, eles sabem onde a gente támexendo.

Pesquisadora: Osprofessores?

Menina: Não. Umas outras pessoas de Brasilia. (Grupo focal $6^{\circ}$ ano).

Menino: Tem jogo privado, que só joga se tu tiver a senha uma conta, dai as pessoas vão querem saber da onde tu é pra te conhecer. [...] Esses chats com jogos são perigosos, às vezes as pessoas vão querem te conhecer, vamos supor, te chamar pra jogar e querem te conhecer uma hora, éperigoso.

Pesquisadora: Isso aconteceu com você?

Menino: Não. (Grupo focal 8a série).

Em nosso entendimento, o que está faltando nos contextos escolares pesquisados é uma regulação do uso do UCA pelos professores e coordenadores pedagógicos. Os alunos chegam à conclusão de que é preciso se autolimitar com as atividades de jogos e bate-papo online, pois experimentam em sua vivência as consequências negativas do vício. Nesta autodelimitação das regras, reconhecemos a falta de mediaçáo do professor.

Um último elemento a ser mencionado é a capacidade das crianças de reconhecerem que aprendem junto ao laptop. Em alguns casos, aprendizagem e inclusão social são apresentadas como aspectos entrelaçados: 
Menina: Eles estão aprendendo mais usando o UCA.

Pesquisadora: Você acha que aprende mais no UCA? Por quê?

Menina: Sim, porque o jogo de matemática se diverte e pode aprendermais.

Pesquisadora: Você acha que quando joga está aprendendo também?

Menina: Sim, tou aprendendo também. (Grupo focal 5० ano).

Menino: (o UCA) ele pode tirar as crianças da rua, das drogas e de outras coisas [...].

Pesquisadora: Porque você acha que pode tirar as crianças das ruas?

Menino: Porque é educativo, ele ensina os meninos, por exemplo, a matemática, tem pessoa que tem dificuldade, é a pior matéria a matemática, ai se tem dificuldade o Uquinha ajuda [...].

Menina: Eu gosto de escrever no UCA, porque quando acaba o caderno nossa máe joga fora e no UCA não, vai ficar aqui, vai ficar salvado e a gente pode depois relembrar e estudar pra prova. (Grupo focal $5^{\circ}$ ano).

Ao contrário do que foi colocado pelos alunos, muitos dos professores entrevistados não reconhecem um processo de aprendizagem nas atividades das crianças. As únicas mudanças que os professores vislumbram são as de caráter técnico e informático. Em alguns casos, também falam em aprendizagem, mas sem circunstanciar ou definir mais aprofundadamente o conceito de "aprender":

Aprendizagem... mas não deixa de ser, né? Aprender a se divertir, a buscar fontes de lazer.. eu acho que isso também é aprendizagem. Eles tem algum progresso nisso. Mas na aprendizagem, assim, de conteúdos, não! (Professora 5a série).

Em cima de tudo eu acho que para a gente utilizar melhor ainda o $U C A$, e realmente fazer esse aprendizado da criança, é a questão do comportamento deles. A questão da disciplina, falta de interesse. Mas aprender eles aprendem, aprendem rápido. [...] Eu aprendo junto com eles também, e eles me ensinam muitas coisas, porque tem uma galera ai que para a área da informática tá com muito mais potencial do que a gente mesmo, porque a geraçâo da gente era outra. [...] Eles aprendem. Eu acho que tudo o que a gente vê, alguma coisa fica. (Professora 6a série).

Algumas poucas, mas significativas, entrevistas destacaram a importância da integraçáo das atividades online dos alunos no cotidiano escolar, na direçáo do que definimos como letramento digital: 
Eu acho que a Internet hoje é a nossa vida! Tudo o que a gente está querendo saber, vai consultar a Internet. Então na sala de aula não pode ser diferente. A gente tem que trazer a Internet no quotidiano da escola. Dentro da sala de aula, temos que trabalhar o nosso quotidiano! [...] Tem que admitir que a gente está ensinando e aprendendo ao mesmo tempo. A gente aprende muita coisa aqui no dia a dia, a gente percebe. (Professor $3^{\mathrm{a}}$ série).

Concluímos esta primeira análise, com a definição de uma resposta muito parcial para a primeira hipótese da pesquisa. As habilidades detectadas não fazem parte de nenhuma das categorias previstas na hipótese. Elas têm mais a ver com a capacidade de se autorregulamentar, aproveitando das possibilidades ofertadas pela Internet na direção da aprendizagem, mais do que das atividades lúdicas.

Nosso passo sucessivo será relacionar estes primeiros dados de pesquisa com a motivação para aprender.

\section{- Um computador por muitos alunos: frustraçáo e desmotivaçáo nas escolas}

O estudo de caso nas quatro escolas selecionadas foi realizado no segundo ou terceiro ano após o início do Projeto UCA. Portanto, deve-se registrar que o número de máquinas quebradas, sem carregador ou com algum problema técnico era, já naquele momento, muito grande. Em 2012, a pesquisa detectou que quase um terço dos laptops das escolas pesquisadas era inutilizável. Assim, a proposta do projeto de ser "Um Computador por Aluno" era, naquelas escolas, já impossível de se manter.

Apontamos esse aspecto, pois em muitas das falas das crianças emergiu certa frustração, devida à falta de manutenção dos equipamentos e a consequente impossibilidade de utilizar os laptops, apesar do desejo. Os seguintes depoimentos resumem muito outros:

Menina: [Desenhei] um velhinho andando de bengala com a pernaquebrada.

Pesquisadora: Porquê?

Menina: Porque a internet é muito lenta.

Pesquisadora: Ea segunda imageméo que?

Menina: É um caminhão carregando um carro quebrado.

Pesquisadora: Por quê?

Menina: Porque o computador estraga muito rápido. (Grupo focal $6^{\circ}$ ano).

Menino: Eu gosto mais ou menos [do UCA] ... assim, mais é bom, ébom.

Pesquisadora: Quando chegou você gostava mais? 
Menino: Quando chegou a gente achando que era um laptop desse aqui mesmo, da Windows e é da CCE. Pode falar a nota do computador? 1,5!

Pesquisadora: Uma nota bem baixa.

Menino: Muito baixo, usa porque não tem nada pra fazer. (Grupo focal $7^{\mathrm{a}}$ série).

Por outro lado, a desmotivação foi encontrada também entre os professores. Este aspecto foi apresentado em dois níveis: uma parte dos entrevistados, afirma que com o UCA a dispersão em sala de aula é muito grande e que os alunos não estão interessados em ouvir o professor; outra parte destaca a falta de formação e de apoio por parte das instituiçóes. A seguir, apresentamos um depoimento por cada categoria, a título de exemplo.

Eu acho que o prejuizo, o problema do UCA, não é o UCA em si, porque é um computador, émídia, para que você tenha essas opçóes, essa liberdade de acessar ... mas precisaria pessoas conscientes. "Não, agora é a hora de eu estudar". Isso não acontece. Não está acontecendo com os cursos superiores, como é que vai acontecer com crianças que não tinham computador e levam ele pra casa? Então imagina a novidade! Quando podem abrir o UCA, é uma festa para eles! "Podemos abrir o UCA? Podemos?"... Mas é um trabalho você dar aula. É muito difícil mesmo. Então, não dá para dizer sié ruim o é bom, porque não tem a ver com o UCA, tá nas pessoas. (Professora 5a série).

Tem esta fragilidade, que eu não acredito que seja da escola, porque criou-se um horário, criou-se o programa de monitoria, buscou-se soluçâo para o carregamento das maquinas, e como é que ainda náo funciona 100\%? [...] são barreiras que são colocadas no processo que acredito que sáo desnecessárias. [...] Eu fico feliz de ter esta experiência porque parece que quando as coisas entram na educação, todo mundo diz: não vai funcionar. $E$ eu sou o movimento completamente contrario. Caiu aqui nesta escola, tem que funcionar mesmo, porque si não a gente não vai caminhar. Vai ficar eternamente colecionando estatística ruim, alto indice de analfabetismo, e achar que isto está normal. E não é normal! [...] Agora, eu fui sempre muito combativa em relação à internet. Estão todos lá, fazendo a sua pesquisa, e a gente está aqui aflita por esta questão. A gente não pode mexer com eletricidade! E eu não posso trazer a conexão à internet! Então, si querem que a gente trabalhe, dêem um minimo de condiçôes a gente. (Professora $3^{\text {a }}$ série).

Destacamos que, na maioria dos casos analisados, o projeto UCA chegou às escolas sem ter sido antecipado por uma análise das necessidades e sem uma consulta prévia aos professores com respeito ao uso que podia ser feito da nova ferramenta. Essa 
falta de participação das escolas na decisão e gestão política do projeto gerou dificuldades - evitáveis em alguns casos -, que levaram os professores a perderem a motivação, gradualmente.

A partir de uma perpectiva ecológica, entendemos a escola como espaço relacional permeado pelas tecnologias e não definido por elas. Porém, o que pudemos perceber com os relatos foi que a inserção destas - de forma "verticalizada", pouco orientada e negociada - acentuou um processo desmotivador que atravessou diversas instâncias da escola, desde o planejamento, passando pela adoção até as relações em sala de aula.

Assim, a percepção desta conjuntura em uma das escolas participantes foi determinante para a realização, na segunda fase da pesquisa, de uma intervenção didático-pedagógica em uma das turmas investigadas. Cabe ressaltar que a intervenção buscou colocar em questão tal momento vivido naquele ambiente. Situação esta que, como apontaremos adiante, acabou se ampliando e mostrando novas nuances das questóes levantadas.

\section{- A flexibilidade do professor como chave para o envolvimento dos alunos}

A proposta do projeto UCA fundamenta-se nos modelos de ensinoaprendizagem de tipo construtivista. Isso significa que o ponto de partida do docente deve ser uma atitude maiêutica frente às crianças e de mediação de sua vontade de descoberta pessoal. Contudo, a observaçáo nos dois campos de pesquisa constatou a presença não só de um, mas de quatro métodos de ensino-aprendizagem, assim delimitados:

1) Metodologia tradicional - o laptop é utilizado como suporte de uma aula expositiva, principalmente para atividades de leitura, em substituição do livro de texto. A metodologia do professor não apresenta diferenças com ou sem a presença da tecnologia;

2) Experimentação limitada - os alunos são chamados para escrever no quadro e estimulados a descobrir as funçôes do laptop seguindo as indicaçôes do professor, que continua sendo o detentor de saber. Registram-se dois limites frequentes nas atividades: o professor não sabe como proceder; as potencialidades da tecnologia náo são plenamente aproveitadas;

3) Experimentaçáo guiada - o professor encoraja os alunos a direcionar seu desejo de descoberta para a realização de atividades com objetivo didático, mostra interesse pelas conquistas dos alunos, tenta integrar uso do laptop e conteúdos disciplinares. As crianças podem levantar, ajudar-se mutuamente e colaborar, o que comporta certa dificuldade de gestão da sala de aula; 
4) Experimentação livre - os alunos têm plena liberdade de experimentar caminhos individuais e criativos de descoberta das funçóes do laptop, sem objetivos didáticos explícitos. À par dos alunos, o professor aprende compartilhando com eles cada novidade. Há pouca ou nula integração do laptop nos conteúdos disciplinares, os alunos encaram a tecnologia principalmente como objeto lúdico.

Em quase todos os casos, a atitude do professor mudou ao longo do período de observação, geralmente no sentido de uma abertura para novas experiências educacionais com o laptop e de troca com as crianças. A positividade dessa abertura é inegável, em termos de desenvolvimento de habilidades e aumento da motivação dos alunos. Em fase de análise de dados, sobressaiu a relaçáo de cada metodologia com certo grau de atenção e participaçáo dos alunos, que os professores frequentemente associaram ora à presença, ora à falta de disciplina. Foi possível observar resultados mais evidentes nos casos em que a metodologia do professor se estabilizou em uma abordagem de Exploração guiada, em que o aluno estava no centro do processo de aprendizagem e o professor assumiu o papel de mediador.

Os professores que mais frequentemente utilizaram um método tradicional são também aqueles que nas entrevistas manifestaram a maior dificuldade em gerir a turma durante as atividades com o laptop e que, ao longo do tempo, acabaram desistindo do projeto. A seguir, o depoimento de uma professora elucida este fato:

E de repente estão lá no Youtube quando você tá ensinando uma coisa completamente diferente... para diversão, para piada, para rir, para estar conversando das coisas deles. Isso vai acontecer igual. Então como eles não vão ter controle, eles simplesmente não usam! [...] A ferramenta é ótima. Eu acho o Google a grande biblioteca mundial. Mas não é o Google que vai te dar a informação, é a traves do Google que você vai chegar no site que você quer. Ai, você precisa se concentrar para fazer o que? Uma leitura, uma seleção. [...] Eu vejo que funciona para alguns, mas quando a criança ela gosta de aprender, ela aprenderia igual com um texto, um livro, um bomfilme.

Quase todos os professores entrevistados disseram que as crianças se tornaram mais hábeis do que eles mesmos, tendo êxitos em atividades que, para eles, são muito complexas. A "abertura" da atitude do professor pode deduzir-se a partir das afirmaçóes que seguiram este reconhecimento de habilidades. Alguns declararam sua firme crença na autonomia das crianças e o desejo de troca mútua; outros mostraram certa preocupação, frente à necessidade de reafirmar, de alguma forma, seu papel de docente; outros deixaram perceber sua admiração pelo que as crianças eram capazes de fazer, mas sem explicitar estas, por medo-acreditamos - de perder sua autoridade. 
Por outro lado, foi possível observar que, quanto mais a cultura da escola e do sistema de ensino é centrada na transferência unilateral de conhecimento, qualquer reconhecimento público da capacidade da criança tem grande ressonância na motivação, atenção, concentração e abandono imediato das atividades lúdicas não relevantes para a aula. Este tipo de reforço da motivação extrínseca normalmente ocorreu por parte dos professores que adotavam uma Metodologia interativa ou de Exploração limitada. Estes foram também os professores que não conseguiram obter dos alunos uma utilização mais disciplinada do laptop.

\section{Projeto UCA: a tecnologia entre ferramenta e cultura}

Entre os aspectos positivos do projeto UCA mencionados pelos professores há, sobretudo, as possibilidades didáticas que a ferramenta apresenta e o aumento da motivação dos alunos, subsequente à chegada do laptop nas escolas. Contudo, os professores, muitas vezes, não souberam explicar em que consistem, concretamente, essas possibilidades didáticas e reconheceram que eles em primeira pessoa não tinham sido capazes de experimentar muito, com a nova ferramenta. Outro elemento positivo nomeado pelos docentes é a "inclusão digital" providenciada pela chegada do laptop, geralmente entendida como acesso físico à tecnologia por parte de crianças de origem humilde e em alguns casos como inclusão social. O último ponto de interesse declarado é o aumento da produtividade e autonomia dos alunos, em uma perspectiva de acentuada melhoria nos processos de aprendizagem. Vista dessa forma, a tecnologia é considerada mais uma "ferramenta" do que uma "cultura", embora nas falas emerja a pressão das "mudanças em curso" que não permitem "voltar atrás”.

Por outro lado, a pesquisa empírica diz respeito a muitos aspectos negativos do projeto UCA, observados na prática em sala de aula e relatados pelos professores. Além dos evidentes limites da máquina, cujo hardware facilmente quebra e cujo software precisa de manutenção técnica frequente, as outras preocupações dos professores são precisamente de caráter didático - em relação à dispersão que o laptop gera na sala de aula -, ou relacionadas às dificuldades de relacionamento entre aluno e professor que surgiram com o uso da ferramenta. Então, junto às possibilidades que o computador representa (teoricamente) para a didática, sobressai uma dificuldade (prática) dos professores na gestáo da sala de aula. Em outras palavras, junto ao reconhecimento teórico da importância da tecnologia no mundo contemporâneo, muitos docentes atentam que um laptop por aluno, na prática cotidiana, atrapalha.

Assim, os resultados da pesquisa mostram como a introdução de uma nova ferramenta tecnológica no ensino, se na fala dos professores representa a oportunidade de rever as crenças no campo educacional, na prática gera insegurança e, às vezes, 
rejeição. Entende-se, ainda, que essa atitude pode facilmente prevalecer, levando não só ao não-acontecimento da inovação didática, mas até ao fortalecimento de hábitos de ensino tradicionais e/ou estabelecidos. Com isso, evidencia-se a dificuldade da tecnologia constituir um espaço de interação e de mediação entre aluno e professor.

Com o intuito de promover práticas reflexivas no âmbito do projeto UCA, optamos pela realizaçáo de uma intervenção didático-pedagógica em um dos campos da pesquisa. Para tanto, nos pautamos na combinação de investigaçáo e intervenção por meio da Mídia-educação - em seu viés ecológico (FANTIN, 2006; PINTO, 2005) - e dos preceitos das Metodologias Participativas (BANDEIRA, 1999; BROSE, 2001; SANTOS, 2005). Dessa forma, enveredamo-nos na busca pela integração das tecnologias digitais móveis na escola, de modo a suplantar a disposiçáo instrumental e determinista de tal uso, e procurando aproximar este contexto à perspectiva da cultura digital. O caminho percorrido será o enfoque do próximo tópico.

\section{As Metodologias participativas no contexto da cultura digital}

De acordo com os dados demonstrados, a presença das tecnologias nos campos pesquisados se traduziu em dificuldades e desafios que, ora esbarravam nas limitaçóes das máquinas - neste caso, os laptops oferecidos pelo projeto UCA -, ora na falta de uma formação "específica" dos professores. Tomados como impeditivos para a prática didático-pedagógica, o binômio formação e tecnologias, segundo os depoimentos, foi o entrave para uma apropriaçáo crítica, criativa e ativa no contexto da escola, culminando, por vezes, na negaçáo ou na dispersão. Com esse cenário, optamos pela realização de uma intervenção didático-pedagógica de forma a ampliar a concepção de conceitos caros à cultura digital como participaçáo, compartilhamento e colaboração, naquele contexto. Para tanto, nos apoiamos nos preceitos de ação-intervençáo das Metodologias Participativas.

\section{Colaboração e participação com Vídeo e Fotografia participativos}

Seguindo os três aspectos principais que nortearam a pesquisa - das quais emergem as hipóteses de investigação e análise -, buscamos a realização de uma intervençáo didático-pedagógica que abarcasse o desenvolvimento de habilidades dos alunos, a motivaçáo pelo processo de ensino-aprendizagem permeado pelo uso das tecnologias digitais, bem como auxiliar o professor frente a esse novo contexto de trabalho. Para a construção das atividades, nos apoiamos nas Metodologias Participativas - com o auxílio dos postulados da Pesquisa-ação e de aproximaçóes ao 
Vídeo e Fotografia participativos -, a fim de compreender o contexto investigado e, ao mesmo tempo, propor uma mudança, mas de modo que ela se pautasse na colaboraçáo e na participação ativa dos sujeitos envolvidos.

De forma breve, o Vídeo Participativo caracteriza-se por ser uma abordagem de comunicação participativa que busca intervenção e mobilização sociais (WHITE, 2003; ZANOTTI, 2013). Na mesma linha, a Fotografia Participativa (MEIRINHO, 2014) também estimula os participantes a refletirem, por meio das representações fotográficas, não só sobre o contexto, mas sobre eles mesmos como integrantes desse "lugar". Nesse sentido, podemos identificar deslocamentos fundamentais para a ocorrência desse enfoque: o professor e/ou pesquisador sáo facilitadores em um processo de ação-reflexão-ação no qual a criação coletiva, ou a produção, e seu potencial reflexivo é mais importante do que seu resultado, ou produto.

Com essa base, a intervenção foi realizada em uma turma do terceiro ano da escola localizada em Florianópolis, também participante da pesquisa. A escolha da turma foi uma proposta conjunta que envolveu a professora, o responsável pela sala informatizada, os gestores do projeto UCA na escola e as pesquisadoras, e oportunizada pela demanda de se propor atividades com o laptop. Dessa forma, as atividades se encaixaram na estratégia de investigar as práticas pedagógicas sob uma perpectiva ecológica da comunicação (BATESON, 1977; PINTO, 2005) e da Mídia-educação (FANTIN, 2006), ou seja, observando os sujeitos e suas interaçóes com os outros, com o ambiente e com a cultura - escolar, social e digital. Assim, buscando abarcar tais elementos teórico-práticos, propusemos um uso combinado dos laptops com as diversas tecnologias disponíveis - câmeras digitais, celulares, computadores de mesa, projetores, entre outros - em variadas situaçóes de aprendizagens e explorando as múltiplas linguagens.

O planejamento desta etapa da pesquisa seguiu três aspectos-chave: o caráter interdisciplinar, com a participação do professor, dos gestores e do professor da sala informatizada (por vezes, os auxiliares de sala juntaram-se às tarefas); a adoção de outras ferramentas e ou tecnologias para além do laptop, ampliando as linguagens trabalhadas; e, por fim, a centralidade no aluno na formulação das situaçóes didáticas. Assim, tendo como base o tema A escola e seu Bairro - previamente negociado entre a professora e os alunos -, as tarefas realizadas envolveram: registro fotográfico pelos alunos do caminho bairro-escola-bairro ${ }^{3}$; entrevistas com moradores (a dona de uma vidraçaria, duas lavadeiras que nasceram no bairro, um senhor dono de um pequeno mercado), utilizando gravadores ou câmeras filmadoras; a criação de um Flipbook com bloquinhos de papel e a produção de uma animação em Stopmotion.

Para a realização, utilizamos como pressupostos os dados obtidos por meio da observação participante, do grupo focal realizado com a turma, bem como dos relatos 
da professora responsável pela turma no momento da intervenção ${ }^{4}$. Na explanação dos resultados observados por ocasiáo da intervençáo didático-pedagógica, pontuaremos nossa análise nas três hipóteses iniciais de pesquisa, elencando alguns episódios da intervenção e dando atenção especial ao caráter colaborativo e participativo.

\section{Colaboraçáo, pertencimento e experimentaçáo: o resgate da agência do aluno}

Seguindo a hipótese da Aquisição de habilidades, corroboramos com a ideia de que as mudanças observadas, e muitas vezes almejadas pelos professores e gestores, dizem respeito ao caráter técnico no uso das tecnologias. Porém, o que observamos durante a intervenção com os alunos, ante a apropriação técnica, foi uma certa prevalência da curiosidade no contato com as ferramentas e suas possibilidades. Cabe ressaltar que nenhum dos alunos possuía celular, apenas três tinham posse do laptop do UCA e, grande parte, nunca havia manipulado uma câmera digital.

Por meio das falas registradas no diário de campo da pesquisa (MIRANDA, 2013), podemos inferir que, antes da apropriação técnica, os alunos se interessaram em compreender e localizar as criaçóes midiáticas no contexto do que podemos entender como cultural do uso das mídias e tecnologias, seja na possibilidade de compartilhamento ou na ânsia pelo registro: "Vamos fazer um filme?!" A menina comemora, para, pensa e pergunta: 'Mas o que é um filme?'. Outros alunos se agitam, parecendo querer responder. Um deles pergunta: "vamos poder passar o nosso filme no Youtube?"(Diário de Campo, 8 out. 2012).

Por causa do pequeno número de alunos que tinham posse do laptop, a professora constantemente emprestava o seu, mas sempre os lembrando sobre a conduta "correta" com a máquina. Tal uso se restringia ao momento do intervalo, ocasiáo na qual alguns alunos que possuíam o laptop se reuniam na biblioteca, localizada ao lado da sala de aula, para uma mesma empreitada: jogar online e em rede. Entendemos que, apesar de demonstrar um caráter colaborativo e se constituir como espaço de aprendizagem - mesmo que não formal -, esta atividade ocorria sem a mediação do professor.

Com base em Gee (2009), entendemos que atividades como os jogos digitais são espaços repletos de possibilidades que se constituem em aprendizagens colaborativas. São formas aprender que compreendem um conjunto de competências e habilidades que envolvem inovaçáo, criatividade e criticidade na resolução de problemas complexos, geralmente realizados de maneira compartilhada.

Dessa forma, entendemos que a falta de mediação em tais atividades assume um duplo papel fragmentador: por um lado impossibilita o envolvimento dos alunos em atividades que abarcam o cotidiano de crianças e jovens - de forma a constituir novos 
cenários pedagógicos -, por outro, reforça a separação da escola, seus métodos e artefatos, desse ambiente que já lhes é familiar no contexto informal.

Assim, ao afastar as aprendizagens que ocorrem "dentro" e "fora" da escola, esta perde a oportunidade de exercer um importante papel mediador na formação crítica e cidadã dos alunos abarcando, para tanto, situaçóes presentes em seus contextos socioculturais, e em circunstâncias caras à contemporaneidade.

$\mathrm{Na}$ conjetura do Um computador por muitos alunos, percebemos certa a frustraçáo presente na fala dos alunos com relaçáo à falta das máquinas, impossibilitadas, seja pela manutenção deficiente ou pelo fato de o aluno náo ter sido contemplado pela política pública no momento da distribuição. Alguns depoimentos demonstram tal fato:

$N a$ ida para as entrevistas, aproveitei para perguntar por que somente um aluno naquele grupo tinha o laptop. Um menino disse que saiu correndo pelos corredores da escola, caiu, machucou o braço e ainda quebrou o laptop. "Mas ainda dava para usar". Mesmo assim, o laptop está na fila do conserto. Uma menina me disse que em um briga com o irmão, ficou com tanta raiva que jogou o laptop dele no chão. "E o seu?", questionei. "Agora é dele”. A outra menina disse que o dela parou de funcionar "não sei por quê". Ele também está no conserto. Os outros dois alunos náo receberamo laptop. Ambos entraram na escola após a distribuição das máquinas. O menino logo se posicionou, com uma fala irritada: "não é justo! E a professora, que entrou depois de mim, já ganhou um!". O menino pediu que eu falasse com o responsável pelos laptops na escola, e intercedesse por ele. (Diário de campo, 24 out. 2012).

Podemos inferir das falas que a falta dos laptops ultrapassa o simples acesso à máquina, demonstrando um caráter de pertencimento. Mesmo que o laptop estivesse "na fila do conserto", a criança se sentia incluída naquele Discurso - que, seguindo Gee (2000), diz respeito a uma vinculaçáo social nos modos de falar, pensar, sentir, agir, de ser e estar no mundo - o que não ocorreu com quem não havia recebido. Contudo, a falta, e a consequente desmotivação, nesse contexto não diz respeito propriamente à máquina, mas à possibilidade de a escola colocar - por meio das práticas pedagógicas - $\mathrm{o}$ compartilhamento e a interação no centro das atividades.

Assim, somente ao organizar-se por meio de uma troca "horizontal" de informaçóes e conhecimentos - que caracteriza as aprendizagens como atos sociais -, a escola poderá subverter o caráter de "uma aprendizagem escolar [que] é a aprendizagem para a escola” (LANKSHEAR; KNOBEL, 2011, p. 67) e se constituir em uma 
comunidade de práticas (WENGER, 2010). Para tanto, tal perspectiva deve se comprometer em como os alunos interagem, produzem e negociam significados uns com os outros (GEE, 2012; LANKSHEAR; KNOBEL, 2011).

Esse dado se relaciona diretamente com a terceira hipótese de pesquisa, que diz respeito à flexibilidade do professor como chave para o envolvimento dos alunos, em dois pontos: o primeiro, mais restrito, diz respeito à impossibilidade do professor de trabalhar com o modelo "Um Computador por Aluno" - devido à, já mencionada, falta dos laptops - e o outro, mais amplo, refere-se à dificuldade do uso das tecnologias em um viés participativo devido ao contexto, arraigado pela metodologia tradicional.

Cabe ressaltar que, entre os alunos, havia uma grande miscelânea no que diz respeito às competências de leitura e escrita: sete dos 23 alunos não estavam alfabetizados, outros dependiam muito da professora nas atividades, enquanto uns pareciam estar muito "adiantados". Com esse cenário, foi possível perceber que, mesmo tendo como orientaçáo as Metodologias Participativas, a busca por um caráter de Experimentação Guiada oscilou entre este e o viés representado, aqui, pela Metodologia Tradicional. Como exemplo, apresentamos algumas dificuldades na realizaçáo da animação em stopmotion, como a pouca participação na construção do roteiro coletivo, que seguiu um tom "ambientalista" ou de "defesa do meio ambiente"; a dificuldade na produção do cenário e a pouca disposição em alguns momentos em que os alunos eram provocados a exporem suas opinióes.

O caráter tradicional apareceu no relato da professora e nas atitudes dos alunos. Segundo ela, os alunos estavam pouco familiarizados com atividades não dirigidas. Assim, nas atividades em sala, eles pareciam buscar a aprovaçáo da professora ou dos gestores para a participação. Essa falta de espontaneidade foi registrada em diversos momentos, por exemplo, no fechamento do audiovisual. Ao serem solicitados a deixarem um depoimento sobre a produção, depois de um longo período em silêncio, um dos alunos optou por uma mensagem "educativa”. Mesmo após ser questionado pela pesquisadora, que pediu que falassem abertamente sobre o que pensaram da atividade ou da experiência, ele esperou o posicionamento e o consentimento da professora para, só então, dar o depoimento. Logo, foi seguido pelos demais:

$\mathrm{K}$ : A gente fez esse vídeo para mostrar o que o ser-humano está fazendo com a natureza.

A: Reciclando e peversando [sic], vamos fazer um mundo melhor.

$\mathrm{R}$ : Amar a natureza sempre ébom. (Trechos do audiovisual),

Esse possível engessamento advindo de um contexto metodológico tradicional acarretou no que Girardello (2014, p. 25) aponta como um "ventriloquismo, que 
ocorre quando os roteiros e performances das crianças ecoam artificialmente os clichês da grande mídia feita pelos adultos". Nesse caso, tal "ventriloquismo" reverberou o contexto da escola para aqueles alunos: vinham de uma tradiçáo educativa realizada por meio de um viés "verticalizado" e unilateral - de ensino sem aprendizagem -, no qual o professor era a autoridade. Isso explica certa postura passível e reativa dos alunos.

Contudo, em atividades que exploraram as representaçôes, como os registros fotográficos, foi possível perceber um caráter participativo dos alunos. Ao retomarmos as fotos tiradas por eles e projetarmos em um telão, eles se reconheciam nos lugares registrados e nos registros, relembrando a autoria de cada foto. Quando o pesquisador questionava sobre os lugares, vários contavam histórias e casos conhecidos por eles em relaçáo à localidade, em um ímpeto narrativo também presenciado nos deslocamentos com os alunos pelo bairro:

A próxima foto projetada era a da entrada da primeira rua do Morro do Quilombo. Perguntei se sabiam que lugar era aquele e logo todos disseram que era o Morro. Um deles apontou e disse que era perto da casa do colega. Sem precisar questionar, uma menina começou a explicar, bem baixinho, o significado de "quilombo". A professora pediu que explicasse para os colegas e ela logo disse: "era o lugar onde moravam uns escravos". O colega ao lado dela completou: "eles iam para lá fugir das pessoas que batiam neles. Por isso eles escolheram o lugar bem no alto, para ninguém chegar lá. Minha mãe me contou.". Este último aluno éum dos que apresenta tem dificuldades em escrita e leitura. (Diário de Campo, 8 out. 2012).

Além dessa fala, os alunos questionaram, relembraram e se posicionaram, a partir das imagens, sobre diversas questôes não só registradas, mas também presenciadas no dia do percurso. Contaram acontecimentos vividos por eles, questionaram sobre o trajeto escolhido por cada um e, também, apontaram para algumas necessidades presenciadas no caminho, como a falta de calçada em um trecho.

Dessa forma, percebemos que as imagens - nesse caso o registro fotográfico do local onde moram - impulsionaram a participaçáo e a colaboração. Ao se identificarem com o lugar, os alunos refletiram sobre a importância de dar atenção náo só aos problemas presenciados na comunidade, como também de conhecerem e se reconhecerem naquele local. Eles se perceberam como representantes do local onde moram e estudam. Nesse momento, identificamos a perspectiva que se centra no aluno e na cultura, ou seja, um processo de ensino-aprendizagem significativo mediado pelo professor. 


\section{Considerações finais}

Com uma orientação prático-reflexiva, a intervenção buscou contribuir para o aprimoramento da prática pedagógica ao tomar os sujeitos envolvidos como autores das produçóes e agentes em suas atuaçóes. Dessa forma, os sujeitos - professores, alunos e pesquisadores - participam do processo pedagógico com o objetivo de compreendê-lo, explicitá-lo e buscando, efetivamente, provocar uma mudança de padrốes estabelecidos, nesse caso, nos modelos tradicionais do uso das tecnologias na escola. Com isso, entendemos que as propostas extrapolaram a concepçáo de modelo UCA que se pauta na relaçáo computador-aluno -, para incidir na afinidade entre aluno e sua aprendizagem (SEVERIN; CAPOTA, 2011), em um contexto atravessado pelas tecnologias digitais.

Contudo, mesmo quando houve a inciativa e pré-disposiçấo dos professores para o uso de tal metodologia, foi possível identificar resquícios do método tradicional na condução das atividades com as tecnologias digitais. $\mathrm{O}$ interessante foi perceber que tal postura tradicional se refletiu também na própria atitude dos alunos que, mesmo nas abordagens de Exploração Guiada, como a intervenção didático-pedagógica proposta, aguardavam o comando do professor para o uso e interação não só com as tecnologias, como também com os colegas.

Assim, ao pautar as Metodologias Participativas em uma perspectiva de açãoreflexão-açáo nas práticas cotidianas da escola, observamos que os desafios que elas nos colocam incidem, sobretudo, em três direçóes:

1) Na definição de ferramentas e atividades criativas, estimulantes e adequadas a uma concepçáo social de aprendizagem;

2) Na necessidade de uma "redefinição" de papéis e lugares de professorespesquisadores, e gestores - que se deslocam do centro para se realocarem ao lado dos alunos, em uma perspectiva "horizontal" do processo de ensinoaprendizagem -, assumindo seu olhar de "dentro" das situaçôes investigadas;

3) A importância da agência das crianças e jovens, que assumem uma nova e ativa posição como coautores de suas próprias aprendizagens e investigaçôes, acompanhada da perspectiva destes como sujeitos do conhecimento, na qual suas vozes e ações são valorizadas, sobretudo, na avaliação dos processos de investigação.

Sendo assim, consideramos que o panorama de produção ou açáo reflexiva, propostos tanto pelo vídeo como pela fotografia participativa, abre a perspectiva de um processo de ensino-aprendizagem pautado na colaboração e participação dos sujeitos. A essa possibilidade, integram-se conceitos como o de multiliteracies ou multiletramentos 
(NEW LONDON GROUP, 2011; COPE; KALANTZIS, 2012) e letramento digital (BUZATO, 2006) - que, de forma breve, referem-se às múltiplas capacidades de ler, compreender, aprender e ensinar no contexto da cultura digital, levando-se em consideraçáo que este é um aprendizado permeado por questóes sociais, culturais e históricas. Significa, assim, abarcar e valorizar os múltiplos saberes, abrindo, igualmente, espaço para os diversos pontos de ser, estar e participar na sociedade e na cultura.

\section{Notas}

${ }^{1}$ ProInfo: Decreto no 6.300 (BRASIL, 2007). PROUCA: Lei no 12.249, de 11 de junho de 2010 .

${ }^{2}$ As observaçôes confirmaram que, muitas vezes, as crianças estavam envolvidas em atividades de entretenimento, como jogos online e chats em redes sociais, durante o horário de aula e, principalmente, sem a permissão do professor.

${ }^{3}$ A maioria dos alunos moravam em uma comunidade carente localizada perto da escola. Dessa forma, o percurso realizado explorou o caminho que vários deles faziam diariamente, alguns a pé, outros de ônibus ou carro. Durante a caminhada, os alunos iam apontando as casas uns dos outros, ou mesmo de parentes e conhecidos.

${ }^{4} \mathrm{O}$ contato com a escola pelas pesquisadoras perdurou todo o ano letivo de 2012 . Nesse período, a professora da turma foi substituída diversas vezes pelas auxiliares de sala, sendo definitivamente substituída por uma professora substituta a partir do mês de setembro do mesmo ano.

\section{REFERÊNCIAS}

BANDEIRA, Pedro. Participação, articulação de atores sociais e desenvolvimento regional. Brasília, IPEA, 1999. (Texto para discussão, n. 630). Disponível em: <http://repositorio.ipea.gov.br/handle/11058/2758>. Acesso em: 9 dez. 2014. BATESON, Gregory. Steps to an ecology of mind: collected essays in anthropology, psychiatry, evolution, and epistemology. London: Jason Aronson Inc., 1977

BELLONI, Maria Luiza. Mídia-educação: contextos, histórias, interrogações. In: FANTIN, Monica; RIVOLTELLA, Pier Cesare (Org.) Cultura digital e escolar: pesquisa e formação de professores. Campinas, SP: Papirus, 2012. p. 31-56.

BOEKAERTS, Monique. Motivation to learn. Educational Practices Series, Geneva, v. 10, 2002. Disponível em:

$<$ http://www.ibe.unesco.org/publications/EducationalPracticesSeriesPdf/prac10e.pdf >. Acesso em: 15 dez. 2014. 
BORUCHOVITCH, Evely; BZUNECK, José Aloyseo (Org.). A motivação do aluno: contribuiçóes da psicologia contemporânea. 4. ed. Petrópolis, RJ: Vozes, 2009.

BROSE, Markus. Metodologia Participativa: uma introdução a 29 instrumentos. Porto Alegre, RS: Tomo Editorial, 2001.

BRANDÁO, Carlos Rodrigues (Org.) Pesquisa participante. 8. ed. São Paulo: Brasiliense, 1999.

BRASIL. Decreto n ${ }^{\circ}$ 6.300, de 12 de dezembro de 2007. Dispóe sobre o Programa Nacional de Tecnologia Educacional -ProInfo. Diário Oficial da União, Brasília, DF, 13 dez. 2007. BRASIL.

BUJOKAS, Alexandra; ROTHBERG, Danilo. La educación en medios y las políticas educativas brasileñas para la mejora del aprendizaje. Comunicar, v. 43, n. 22, Huelva, p. 113-122, 2014. Disponível em: $<$ http://www.revistacomunicar.com/index.php?contenido=detalles\&numero=43\&art iculo $=43-2014-11>$. Acesso em: 8 nov. 2014.

BUZATO, Marcelo. Letramentos digitais e formação de professores. In: CONGRESSO IBERO-AMERICANO EDUCAREDE, 3., 2006, São Paulo. Anais... São Paulo: CENPEC, 2006.

COPE, Bill; KALANTZIS, Mary. Multiliteracies: literacy learning and the design of social futures. New York: Routledge, 2012.

FANTIN, Monica. Mídia-educaçâo: conceitos, experiências, diálogos Brasil-Itália. Florianópolis, SC: Cidade Futura, 2006.

FANTIN, Monica; RIVOLTELLA, Pier Cesare (Org.). Cultura digital e escola: pesquisa e formação de professores. Campinas, SP: Papirus, 2012.

FREIRE, Paulo. Extensão ou comunicação? São Paulo: Paz e Terra, 2011.

FREINET, Celéstin. O Jornal escolar. Lisboa: Estampa, 1974.

JENKINS, Henry. Confronting the challenges of participatory culture: media education for the 21st Century. Chicago: MacArthur Foundation, 2011. Disponível em:

<http://www.macfound.org/media/article_pdfs/JENKINS_WHITE_PAPER.PDF>. Acesso em: 8 nov. 2014. 
GEE, James Paul. Discourse and sociocultural studies in reading. Reading Online, Newark, v. 4, n. 3, 2000. Disponível em:

$<$ http://www.readingonline.org/articles/art_index.asp?HREF=/articles/handbook/ge e/index.html>. Acesso em: 5 nov. 2012.

GEE, James Paul. Bons videogames e boa aprendizagem. Perspectiva, Florianópolis, SC, v. 27, n. 1, p. 167-178, jan./jun. 2009. Disponível em:

$<$ https://periodicos.ufsc.br/index.php/perspectiva/article/view/2175-

795X.2009v27n1p167/14515>. Acesso em: 5 nov. 2012.

GEE, James Paul. New people in new worlds: networks, the new capitalism and schools In: COPE, Bill; KALANTZIS, Mary. Multiliteracies: literacy learning and the design of social futures. New York: Routledge, 2012. p. 43-69.

GIRARDELLO, Gilka. Crianças fazendo mídia na escola: desafios da autoria e da participação. In: ELEÁ, Ilana. Agentes e Vozes: um panorama da Mídia-educação no Brasil, Portugal e Espanha. Gothenburg: Nordicom, 2014. p. 21-29.

GIRARDELLO, Gilka; OROFINO, Maria Isabel. Crianças, cultura e participação: um olhar sobre a mídia-educação no Brasil. Comunicação, Mídia e Consumo, São Paulo, v. 9, n. 25, p. 73-90, 2012 Disponível em:

<http://revistacmc.espm.br/index.php/revistacmc/article/view/312>. Acesso em: dez. 2012.

GLASER, Barney; STRAUSS Anselm. The discovery of grounded theory. New York: Aldine, 1967.

LANKSHEAR, Colin; KNOBEL, Michelle. Nuevos Alfabetismos: su práctica cotidiana y el aprendizaje en el aula. 3. ed. Madrid: Morata, 2011.

LEMOS, André. Ciberespaço e tecnologias móveis: processos de territorialização e desterritorialização na cibercultura. In: MÉDOLA, Ana Silvia; ARAUJO, Denise; BRUNO, Fernanda (Org.). Imagem, visibilidade e cultura midiática. Porto Alegre: Sulina, 2007. p. 277-293.

MEIRINHO, Daniel. Olhares em Foco: um projeto de fotografia participativa para o desenvolvimento social de jovens no Brasil e em Portugal. In: ELEÁ, Ilana. Agentes e vozes: um panorama da Mídia-educação no Brasil, Portugal e Espanha. Gothenburg: Nordicom, 2014. p. 187-197.

MIRANDA, Lyana V. T. Multissensorialidades e aprendizagens: usos das tecnologias móveis pelas crianças na escola. 2013. Dissertação (Mestrado em Educação) Universidade Federal de Santa Catarina, 2013. 
NEW LONDON GROUP. A pedagogy of multiliteracies: designing social futures. Harvard Educactional Review, Massachusetts, v. 66, n. 1, 1996. Disponível em: $<$ http://www.newliteracies.com.au/what-are-new-literacies?/138/>. Acesso em: 15 out. 2011.

PINTO, Manuel. A busca da comunicação na sociedade multi-ecrãs: perspectiva ecológica. Comunicar, Huelva, n. 25, p. 259-264, 2005. Disponível em: $<$ http://www.revistacomunicar.com/verpdf.php?numero=25\&articulo=25-2005036>. Acesso em: 15 out. 2011.

PISCHETOLA, Magda. Educazione e divario digitale: idee per il capacity building. Milano: Unicopli, 2011.

PISCHETOLA, Magda. Teaching with laptops: a critical assessment of one-to-one technologies. In: STOCCHETTI, Matteo (Org.). Media and education in the digital age: concepts, assessments, subversions. Berlin: Peter Lang, 2014. p. 203-214.

RIVOLTELLA, Pier Cesare. Retrospectivas e tendências da pesquisa em Mídiaeducação no contexto internacional. In: FANTIN, Monica; RIVOLTELLA, Pier Cesare (Org.) Cultura digital e escolar: pesquisa e formação de professores. Campinas, SP: Papirus, 2012. p. 57-94.

SANTOS, Ailton Dias. Metodologias Participativas: caminhos para o fortalecimento de espaços públicos socioambientais. São Paulo: Peirópolis, 2005.

SEVERÍN, Eugenio; CAPOTA, Christine. La computación uno a uno: nuevas perspectivas. Revista Ibero-americana de educação, n. 56, p. 31-48, 2011.

THIOLLENT, Michel. Metodologia da pesquisa-ação. São Paulo: Cortez, 2000.

TRIPP, David. Pesquisa-ação: uma introdução metodológica. Educação e Pesquisa, São Paulo, v. 31, n. 3, p. 443-466, set./dez. 2005. Disponível em:

<http://www.scielo.br/pdf/ep/v31n3/a09v31n3.pdf >.Acesso em: 28 nov. 2012.

WENGER, Etienne. Communities of practice and social learning systems: the career of a concept. In: BLACKMORE, Chris (Org). Social learning and communities of practice. Grass Valley: Spring Verlan and the Open University, 2010. Disponível em: <http://wenger-trayner.com/resources/publications/cops-andlearning-systems/>. Acesso em: 12 dez. 2014.

WHITE, Shirley. A; NAIR, Sadanandan. Cultural renewal: an operational model for sharing diversity through participatory communication. Annual Meeting of the International Communication Association, Sydney, 1994. Disponível em: <http://files.eric.ed.gov/fulltext/ED372436.pdf>. Acesso em: 10 nov. 2014. 
WHITE, Shirley A. Participatory Video: images that Transform and Empower. New York: Sage Publications, 2003.

ZANOTTI, Ana. Olhares em progresso, olhares em processo: uma experiência de vídeo participativo com jovens que habitam um espaço fronteiriço. Iluminuras, Porto Alegre, v. 14, n. 32, p. 123-145, jan./jun. 2013. Disponível em: <http://seer.ufrgs.br/iluminuras/article/view/37747>. Acesso em: 15 maio 2014. 


\section{Participatory methods and UCA project: the search of technology as culture}

\section{Abstract}

In the complex and changing context of digital culture, the medias become an important space for education, as they have the crucial role of articulating new cultural logics that lead to disruptions in the school environment. To understand this change, new methods of analysis and research have been created, the so-called Participatory Methodologies. They are action research strategies that aimed at intervening in a given social situation. In the analysis proposed here, such methodologies will help us to address the challenge of involving digital technologies in school culture, through the participation of different individuals involved. Two qualitative case studies about the Project One computer per student Projeto Um Computador por Aluno (UCA) -, carried out in 2012 in the schools of Santa Catarina and Bahia, are the first of two phases of the research presented. The results concern a "vertical" form of technology insertion at schools, which led to frustration and demotivation at several levels. Starting from these considerations, the second stage of research proposes a pedagogical intervention in one of the four schools. The methodologies of participatory video and photography are chosen as possibilities of action-reflectionaction on the sociocultural reality of students through the experience of sharing. The results show the importance of carrying out creative activities, appropriate to a social conception of learning, as well as the centrality of children and youth agency and a broader need to redefine the relationship between teacher and
Méthodes Participatives et Projeto UCA: les technologies de l'information et de la communication vues comme une culture

\section{Résumé}

Dans le contexte complexe et changeable de la culture numérique, les médias deviennent comme un important espace pour la formation et l'articulation de nouvelles logiques culturelles qui conduisent à des ruptures dans l'environnement scolaire. Pour comprendre ce changement, des nouvelles méthodes d'analyse et de recherche sont développés, comme les Méthodes Participatives. Ils sont des stratégies de recherche et d'action qui visent intervenir dans une situation sociale. Ces méthodes de recherche nous aideront à affronter le défi d'impliquer les technologies de la communication dans la culture propre de l'école, au moyen de la participation de différentes personnes impliquées. Deux études de cas qualitatives sur le projet Un Ordinateur par Enfant (One Laptop per Child brésilienne), a été réalisée en 2012 dans les écoles de Santa Catarina et de Bahia. Les résultats concernent a une forme "verticale» de l'insertion des technologies de la communication dans les écoles, ce qui a conduit à la frustration et démotivation à plusieurs niveaux. A partir de ces considérations, nous avons proposé une intervention pédagogique et didactique dans une des quatre écoles investigueés. Les méthodologies de vidéo et de la photographie participative sont choisies comme possibilités d'action-réflexion-action sur la réalité socioculturelle des élèves à travers les expériences partageés. Les résultats montrent l'importance de mener des activités créatives 
student, in a more "horizontal" perspective of teaching and learning process.

Keywords: UCA Project. Participatory Research Method. Education for Participation. appropriées à une conception sociale de l'apprentissage, de la centralité d'agence des enfants et des jeunes, et un besoin de redéfinir la relation entre l'enseignant et l'élève, dans une perspective plus «horizontale» de le processus d'enseignement et d'apprentissage..

Mots-clés: Projeto UCA. Méthodologie participative. Enseignement-apprentissage innovatif. 


\section{Magda Pischetola}

E-mail:magda@puc-rio.br

\section{Lyana Thediga Miranda}

E-mail: lyanathediga@gmail.com

Recebido em: 15/12/2014 Aprovado em: 21/03/2015 